\title{
Integración comercial y diversificación de las exportaciones: el caso de las relaciones comerciales de El Salvador con los Estados Unidos y Centroamérica ${ }^{1}$
}

\author{
Raúl Vázquez López y Rodrigo Alfonso Morales López
}

\section{Resumen}

En este artículo se hace un análisis comparativo entre la diversificación de la canasta exportadora de El Salvador hacia los Estados Unidos y hacia Centroamérica. Se utiliza el máximo nivel de desagregación disponible y se organizan los productos de acuerdo con la intensidad tecnológica que tienen incorporada. Los resultados muestran que el nivel de diversificación y sofisticación exportadora es superior en las transacciones comerciales con Centroamérica. También se encuentra evidencia de que, en el caso de El Salvador, es más conveniente fortalecer la integración Sur-Sur, en especial la centroamericana, que la integración Norte-Sur.

\section{Palabras clave}

Integración económica, relaciones económicas, comercio internacional, comercio intrarregional, exportaciones, diversificación de las exportaciones, análisis comparativo, estadísticas comerciales, El Salvador, Estados Unidos, Centroamérica

\section{Clasificación JEL}

F15, F13, F43, F14

\section{Autores}

Raúl Vázquez López es Investigador Titular "C" en la Unidad de Economía Industrial del Instituto de Investigaciones Económicas de la Universidad Nacional Autónoma de México. Correo electrónico: rvazquez@unam.mx.

Rodrigo Alfonso Morales López es Doctorando en Economía Internacional del Instituto de Investigaciones Económicas de la Universidad Nacional Autónoma de México. Correo electrónico: ramorales88@gmail.com.

\footnotetext{
1 Investigación realizada gracias al Programa de Apoyo a Proyectos de Investigación e Innovación Tecnológica (PAPIIT) <IN302815>.
} 


\section{Introducción}

A partir de los años ochenta, en la mayoría de los países en desarrollo se implementaron una serie de políticas inspiradas en los lineamientos económicos promovidos por el consenso de Washington. En el caso de El Salvador, desde 1989 las políticas gubernamentales se han encaminado hacia la puesta en práctica de estas directrices. Tal como ocurrió en diversos países en desarrollo, se buscó la liberalización comercial, la apertura a la entrada de inversiones extranjeras directas, las privatizaciones y distintos tipos de desregulación económica, en el supuesto de que dichas medidas impulsarían el crecimiento económico y, en consecuencia, el nivel de vida de la población. En el área comercial, la estrategia consistió en lograr una apertura basada en la desgravación arancelaria, la eliminación de barreras no arancelarias y la firma de diversos tratados de libre comercio (Lara, 2003).

El eje de la política comercial ha sido la negociación y ejecución de diversos tratados de libre comercio, entre los cuales el más emblemático es el Tratado de Libre Comercio entre la República Dominicana, Centroamérica y los Estados Unidos. En diciembre de 2004, El Salvador fue el primer país de la región en ratificar este acuerdo, que entró en vigor el 1 de marzo de 2006. El primer objetivo que se planteó en el documento original del tratado era "estimular la expansión y diversificación del comercio entre las partes” (Calderón, González y Sanabria, 2008).

Otra medida comercial importante que se adoptó en la región a inicios de los años noventa fue el relanzamiento de la integración centroamericana, en la que se plantea la consecución de una unión económica plena entre los países miembros². Una de las fases previas para lograr tal objetivo era concretar la unión aduanera. Sin embargo, debido a factores internos y externos, entre los que se destaca el reciente relego del tema debido al libre comercio bilateral, la unión aduanera aún no se concreta en su totalidad (Guerra-Borges, 2009). De hecho, los acuerdos centroamericanos de integración están subordinados a tratados de libre comercio como el Tratado de Libre Comercio entre la República Dominicana, Centroamérica y los Estados Unidos (Caldentey del Pozo, 2010).

Ante este escenario, y en el marco del presente trabajo, se proponen dos objetivos. El primero es estudiar los vínculos existentes entre la integración comercial Norte-Sur o Sur-Sur, y el grado de diversificación y sofisticación de las exportaciones. El segundo es identificar los factores que determinan que el grado de diversificación y sofisticación de las ventas al exterior sea diferente cuando se trata de relaciones comerciales Norte-Sur o Sur-Sur. Para alcanzar ambos objetivos se estudia el caso de las relaciones comerciales de El Salvador con Centroamérica (integración Sur-Sur) y los Estados Unidos (integración Norte-Sur), en el período comprendido entre 2005 y 2015. El principal aporte de esta investigación es que se compara la diversificación y sofisticación de las exportaciones salvadoreñas hacia los Estados Unidos y hacia Centroamérica, usando el mayor nivel de detalle disponible en las estadísticas oficiales del país y organizando los productos de acuerdo con su contenido tecnológico. Además, de los resultados obtenidos se desprenden implicaciones normativas relevantes para la política comercial de El Salvador y potencialmente para la de otros países en desarrollo, en especial los de la región centroamericana.

La organización del artículo es la siguiente: en el segundo apartado se analizan las vinculaciones teóricas entre la integración comercial y la diversificación de las exportaciones, y se resumen los hallazgos principales de algunas investigaciones previas relacionadas con el tema; en el tercero se hacen las precisiones necesarias acerca del enfoque metodológico utilizado y se detallan las fuentes de información, las nomenclaturas del comercio internacional, los niveles de desagregación, las correspondencias y los indicadores utilizados; en el cuarto se hace un análisis comparativo entre el grado de diversificación de las exportaciones dirigidas hacia los Estados Unidos y el de las destinadas a Centroamérica, y, por último, en el quinto apartado se presentan las principales conclusiones del trabajo y se realizan algunas aportaciones normativas sobre el tema.

2 En este trabajo, la región centroamericana está conformada por Guatemala, El Salvador, Honduras, Nicaragua y Costa Rica. 


\section{Elementos de análisis sobre la integración comercial y la diversificación de las exportaciones}

La globalización económica se ha materializado en la existencia de nuevas formas de organizar la producción que dan lugar a una fragmentación y relocalización geográfica de las tareas industriales. Esto da origen a una división internacional del trabajo entre los países, que termina por limitar las opciones de desarrollo de los países menos desarrollados, los cuales, por sus características, tienden a ubicarse en los estratos de la producción mundial cuyo valor agregado es bajo (Gereffi, 1996). En la mayoría de los casos, son las corporaciones multinacionales las que deciden dónde se localiza cada segmento productivo de las cadenas mundiales de valor de acuerdo con el nivel de los costos laborales o la ubicación geográfica (Ernst, 2003). Gereffi (1996) sostiene que la clave para que un país en desarrollo logre escalar en las cadenas mundiales de valor depende en gran medida de los roles exportadores que asuma y de su habilidad para avanzar hacia nichos más sofisticados. En el caso de la economía de Centroamérica, su posición e importancia en las cadenas mencionadas se encuentra marcada por las operaciones que realiza la industria maquiladora en la región.

En este contexto se enmarcan los diversos acuerdos de integración comercial existentes, ya sean de carácter Norte-Sur o Sur-Sur. En esta investigación, se utiliza la definición de integración de Cohen Orantes (1981): "la integración es un proceso mediante el cual dos o más gobiernos adoptan, con el apoyo de instituciones comunes, medidas conjuntas para intensificar su interdependencia y obtener así beneficios mutuos". De acuerdo con Caldentey del Pozo (2000), la integración no es un objetivo en sí mismo, sino que debe ser un instrumento de desarrollo económico y social para los países miembros. Como todo proceso, la integración se puede dividir en diferentes fases o etapas: el área o zona de libre comercio, la unión aduanera, el mercado común y la unión económica (Balassa, 1980).

Los efectos de la integración en la economía se catalogan como estáticos o dinámicos. El análisis estático está fundamentado en el trabajo pionero de Viner (1950) sobre uniones aduaneras. Estos efectos se analizan de acuerdo con la creación de comercio (ganancias de bienestar) y la desviación del comercio (pérdidas de bienestar). Por otro lado, entre los efectos dinámicos se destacan los siguientes: mejora de la eficiencia económica, creación de economías de escala, aumento de la inversión, estímulo del desarrollo tecnológico y mejoras de los términos de intercambio (Caldentey del Pozo, 2000). Según Requeijo (1995) son los aspectos dinámicos los que justifican las políticas destinadas a promover la integración Sur-Sur.

Sin embargo, Schweickert (1994) señala que, para un país en desarrollo, la integración Norte-Sur es más efectiva porque los efectos estáticos permiten obtener mayores ganancias en el corto plazo. Con respecto a los efectos dinámicos, varios autores señalan que en la integración Norte-Sur hay un derrame tecnológico mayor que en la Sur-Sur, lo que propicia el desarrollo de industrias intensivas en conocimiento (Schiff, Wang y Olarreaga, 2002; Coe y Helpman, 1995). Estas ideas sobre la integración Norte-Sur son las que han definido, desde la década de 1990, la política comercial de El Salvador, cuyo mayor exponente es el Tratado de Libre Comercio entre la República Dominicana, Centroamérica y los Estados Unidos. Sin embargo, los beneficios de la integración Norte-Sur se encuentran fundamentados en la teoría ortodoxa del comercio exterior, en la que tradicionalmente se enfatiza la relevancia de especializarse en aquellos sectores con abundancia relativa de un factor de producción y, por tanto, no se toman en cuenta los aspectos recientes del comercio internacional antes mencionados, que están ligados al funcionamiento de las cadenas mundiales de valor y son propios del comercio intraindustrial. 
Los beneficios de la integración entre los países en desarrollo también han sido documentados por varios autores. Entre dichos beneficios, el que más atañe a esta investigación es el vínculo positivo entre la integración Sur-Sur y la diversificación de las exportaciones.

Al respecto, Regolo (2013) sostiene que las exportaciones hacia países con dotaciones similares de factores son más diversificadas que las exportaciones hacia países con dotaciones diferentes. Además, señala que, cuanto menores son los costos asociados al comercio, mayor es el grado de diversificación. Sanguinetti, Pantano y Posadas (2004) encuentran que otra posible explicación de la relación causal positiva entre la integración horizontal de los países en desarrollo y el aumento de la diversificación de las exportaciones puede estar vinculada con el fomento de las economías de escala entre los países miembros. Bekerman y Rikap (2010) encuentran que, en el entorno de la integración regional del MERCOSUR, la Argentina y el Brasil lograron diversificar su canasta exportadora mediante la creación de nuevas ventajas comparativas. Dicho efecto se atribuye a que el MERCOSUR actuó como una plataforma inicial para desarrollar procesos de innovación productiva y organización que permitieron aprender y lograr economías de escala, condiciones que luego repercutieron en la diversificación de las exportaciones tanto hacia dentro del bloque integrador como hacia fuera. En el aparataje teórico utilizado por Bell y Pavitt (1992), la integración horizontal Sur-Sur beneficia el desarrollo no solo de las capacidades productivas, sino también de las capacidades tecnológicas.

Los canales de transmisión entre la integración Sur-Sur y la diversificación de las exportaciones son los menores costos asociados al comercio (en el caso de países cercanos desde el punto de vista geográfico), el fomento de las economías de escala entre los países integrados, la creación de nuevas ventajas comparativas y el desarrollo de las capacidades productivas y tecnológicas. Estos mecanismos están íntimamente relacionados con los efectos dinámicos que la integración tiene en la economía y también con los que la diversificación exportadora tiene en el crecimiento económico de los países en desarrollo ${ }^{3}$. Por lo tanto, según esta postura teórica, son deseables los esquemas de integración Sur-Sur con los que se busque promover la diversificación de las exportaciones. Se espera, en suma, que el grado de diversificación de la canasta de exportaciones de un país en desarrollo sea más amplio en las relaciones comerciales que sostiene con otros países en desarrollo que en las que sostiene con economías más desarrolladas.

La condición necesaria para que funcionen los mecanismos de transmisión entre la integración Sur-Sur y la diversificación de las exportaciones es la existencia de derrames tecnológicos que propicien una difusión del conocimiento. Al respecto, varios autores ligados a la geografía económica sostienen que la "diversificación relacionada" promueve de manera efectiva los derrames tecnológicos (Boschma e lammarino, 2009; Frenkel, Van Oort y Verburg, 2007), fortalece de esta manera las capacidades productivas y tecnológicas de los países en desarrollo, y promueve el escalamiento en las cadenas mundiales de valor ${ }^{4}$. No obstante, en el área de la geografía económica también se reconoce la importancia de la "diversificación no relacionada" como mecanismo de amortiguación ante una posible crisis dentro de un sector o sectores relacionados, que mejora la estabilidad económica en el largo plazo (Essletzbichler, 2005).

De lo anterior se puede establecer que la integración Sur-Sur (como la de EI Salvador-Centroamérica) podría favorecer la diversificación de las exportaciones en mayor medida que la Norte-Sur (como las de los Estados Unidos-El Salvador), al generar efectos dinámicos que repercutirían de manera positiva en el crecimiento. De hecho, en los países en desarrollo, la integración de tipo Norte-Sur

3 Los efectos dinámicos de la diversificación de las exportaciones en el crecimiento de los países en desarrollo se pueden resumir en el aumento de la productividad, la mejora de las capacidades tecnológicas y productivas, el autodescubrimiento de nuevos productos, el encadenamiento de las actividades de fabricación, la sofisticación productiva creciente, y la formación y el fortalecimiento de economías de escala y externalidades (Samen, 2010; Agosin, 2009).

4 El término utilizado originalmente en la geografía económica es "variedad relacionada" y se refiere a la diversificación de las exportaciones que ocurre dentro de un grupo de productos que presentan complementariedades entre sí y cuya producción requiere de competencias similares. 
se ha promovido con la idea de especializar al país atrasado en el factor que es abundante y no de diversificar su canasta exportadora.

En el caso de El Salvador no existen estudios en los que se empleen las concepciones teóricas y la metodología empírica de este estudio. Sin embargo, sí hay investigaciones similares sobre la diversificación de las exportaciones o la intensidad tecnológica en las que se usan metodologías parecidas o se analiza la región centroamericana en su conjunto.

Martínez y Cortés (2004) usan programas especializados (TradeCAN y MAGIC) para analizar la competitividad internacional de las exportaciones de Centroamérica durante el período 1990-2002. Entre sus principales hallazgos resalta el que se refiere a que el comercio intrarregional se compone principalmente de rubros industriales. De igual forma, hallan que la mayoría de los 20 rubros que más peso tienen en las exportaciones centroamericanas hacia el mercado intrarregional son dinámicos ${ }^{5}$. Con respecto al comercio con los Estados Unidos, sostienen que, a pesar de la mayor presencia de bienes industriales dinámicos en las exportaciones, en términos generales ostenta un predominio el rubro textil, ligado principalmente a la industria maquiladora (Martínez y Cortés, 2004).

Beteta y Moreno-Brid (2014) proponen que en Centroamérica es necesario hacer un cambio estructural que propicie un círculo virtuoso de crecimiento mediante la diversificación y la densificación de la estructura productiva, la innovación y la distribución más igualitaria del ingreso. Además, señalan que, para obtener mayores beneficios del proceso de integración, los países de Centroamérica deben producir y exportar un mayor valor agregado local, generar empleos de calidad, aprovechar el dinamismo del sector de los servicios, promover encadenamientos productivos locales, fortalecer el mercado intrarregional y mejorar la coordinación entre las políticas públicas regionales. De manera concisa, los autores reconocen la importancia de avanzar en la integración económica centroamericana y en la promoción de una política que diversifique la estructura productiva y exportadora. Además, señalan que la inserción de Centroamérica en las cadenas mundiales de valor ha carecido del dinamismo que se observa en otras partes del mundo y adjudican este hecho a que dicha inserción se produce mayoritariamente mediante la industria maquiladora y las zonas francas de procesamiento para la exportación.

Schatan y otros (2008) se proponen analizar si la integración regional centroamericana y el Tratado de Libre Comercio entre la República Dominicana, Centroamérica y los Estados Unidos son medidas complementarias entre sí o si, por el contrario, ese tratado debilita el proceso de integración regional. De acuerdo con dicho estudio, el comercio intrarregional se compone principalmente de manufacturas no ensambladas y, por lo tanto, aporta un mayor valor agregado y genera mayores oportunidades para las pequeñas y medianas empresas (pymes) que las exportaciones extrarregionales, incluidas las que se enmarcan en el mencionado tratado.

Amaya y Cabrera (2013) usan la técnica denominada "espacio de producto" y calculan la proximidad, complejidad y productividad de los productos exportados por El Salvador, utilizando un nivel de desagregación de dos dígitos de la Revisión 2 de la Clasificación Uniforme para el Comercio Internacional (CUCl Rev.2). Emulando las investigaciones pioneras en las que se emplea este enfoque metodológico, los autores utilizan el número de productos con ventaja comparativa revelada como indicador de la diversificación de las exportaciones (véase Hausmann, Hwang y Rodrik, 2007). En el trabajo empírico se sostiene que El Salvador debe diversificar su canasta exportadora para lograr mejores encadenamientos con el resto de la economía y alcanzar un crecimiento económico inclusivo.

\footnotetext{
5 Martínez y Cortés (2004) utilizaron el programa MAGIC con un nivel de desagregación de cuatro dígitos del Sistema Armonizado de Designación y Codificación de Mercancías (SA). En la metodología del TradeCAN, las exportaciones de un bien se consideran dinámicas cuando la participación del país exportador se incrementa en un mercado cuya demanda de ese bien es creciente.
} 


\section{Metodología}

La fuente de información para llevar a cabo esta investigación es la base de datos de comercio exterior del Banco Central de Reserva de El Salvador. Se utilizaron los datos a nivel de ocho dígitos del Sistema Arancelario Centroamericano (SAC). El SAC se basa en el Sistema Armonizado de Designación y Codificación de Mercancías (SA) de la Organización Mundial de Aduanas, sin bien las revisiones que dicha organización le hace a ese sistema no se implementan inmediatamente en el SAC. En la práctica, este último es una combinación de distintas revisiones del SA.

La información obtenida se redujo a nivel de seis dígitos con la finalidad de utilizar las correspondencias de la Solución Comercial Integrada Mundial (WITS, 2016) y trasladar el SAC de seis dígitos (combinación del SA de seis dígitos) al SA 1988/92 de seis dígitos. Para realizar este proceso se utilizaron las correspondencias elaboradas por medio de la WITS (2016), a saber:

- $\quad$ SA $1996 \rightarrow$ SA 1988/92

- $\quad$ SA $2002 \rightarrow$ SA 1988/92

- $\quad$ SA $2007 \rightarrow$ SA 1988/92

- $\quad$ SA $2012 \rightarrow$ SA 1988/92

- $\quad$ SA combinado $\rightarrow$ SA 1988/92

Se consolidó toda la información utilizando la clasificación SA 1988/92 para obtener 5.017 productos (códigos de seis dígitos del SA 1988/92). Posteriormente, se utilizó una correspondencia adicional descargada de la WITS (2016) para trasladar los datos a la CUCI Rev. 2. Dicha correspondencia permite trasladar los seis dígitos del SA 1988/92 al nivel de cuatro o cinco dígitos de la CUCI Rev. 2, que luego se redujo a tres dígitos con la finalidad de utilizar el cuadro propuesto por la Comisión Económica para América Latina y el Caribe (CEPAL), a fin de reagrupar los bienes según su intensidad tecnológica incorporada (véase el cuadro 1). Este cuadro se extrajo de Durán Lima y Álvarez (2011) y en él se clasifican los códigos de tres dígitos de la CUCl Rev.2 en seis categorías y 11 grupos.

\section{Cuadro 1}

Clasificación del comercio según la intensidad tecnológica incorporada

\begin{tabular}{|c|c|}
\hline Categoría & Códigos de tres dígitos de la Clasificación Uniforme para el Comercio Internacional, revisión 2 \\
\hline 1. Bienes primarios & $\begin{array}{l}001,011,022,025,034,036,041,042,043,044,045,054,057,071,072,074 \\
075,081,091,121,211,212,222,223,232,244,245,246,261,263,268 \\
271,273,274,277,278,281,286,287,289,291,292,322,333,341 .\end{array}$ \\
\hline \multirow[t]{2}{*}{$\begin{array}{l}\text { 2. Manufacturas basadas } \\
\text { en recursos naturales }\end{array}$} & $\begin{array}{l}\text { 2.1. Productos industrializados agrícolas o forestales } \\
012,014,023,024,035,037,046,047,048,056,058,061,062,073,098,111,112,122, \\
233,247,248,251,264,265,269,423,424,431,621,625,628,633,634,635,641 .\end{array}$ \\
\hline & $\begin{array}{l}\text { 2.2. Otros productos basados en recursos naturales } \\
\text { 282, } 288,323,334,335,411,511,514,515,516,522,523,531,532,551,592, \\
661,662,663,664,667,681,682,683,684,685,686,687,688,689 .\end{array}$ \\
\hline \multirow[t]{2}{*}{$\begin{array}{l}\text { 3. Manufacturas de } \\
\text { baja tecnología }\end{array}$} & $\begin{array}{l}\text { 3.1. Productos textiles y de moda } \\
611,612,613,651,652,654,655,656,657,658,659,831,842,843,844,845,846,847,848,851 .\end{array}$ \\
\hline & $\begin{array}{l}\text { 3.2. Otros productos de baja tecnología } \\
642,665,666,673,674,675,676,677,679,691,692,693,694 \\
695,696,697,699,821,893,894,895,897,898,899 .\end{array}$ \\
\hline \multirow[t]{3}{*}{$\begin{array}{l}\text { 4. Manufacturas de } \\
\text { tecnología media }\end{array}$} & $\begin{array}{l}\text { 4.1. Productos automotrices } \\
781,782,783,784,785 .\end{array}$ \\
\hline & $\begin{array}{l}\text { 4.2. Industrias de procesos de tecnología media } \\
\text { 266, 267, 512, 513, 533, 553, 554, 562, 572, 582, 583, 584, 585, } \\
591,598,653,671,672,678,786,791,882 \text {. }\end{array}$ \\
\hline & $\begin{array}{l}\text { 4.3. Industrias de ingeniería de tecnología media } \\
711,713,714,721,722,723,724,725,726,727,728,736,737,741,742,743, \\
744,745,749,762,763,772,773,775,793,812,872,873,884,885,951 .\end{array}$ \\
\hline
\end{tabular}


Cuadro 1 (conclusión)

\begin{tabular}{ll}
\hline Categoría & Códigos de tres dígitos de la Clasificación Uniforme para el Comercio Internacional, revisión 2 \\
\hline $\begin{array}{l}\text { 5. Manufacturas de } \\
\text { alta tecnología }\end{array}$ & $\begin{array}{l}\text { 5.1. Productos eléctricos y electrónicos } \\
\text { 716, 718, 751, 752, 759, 761, 764, 771, 774, 776, 778. }\end{array}$ \\
\cline { 2 - 2 } & $\begin{array}{l}\text { 5.2 Otros productos de alta tecnología } \\
\text { 524, 541, 712, 792, 871, 874, 881. }\end{array}$ \\
\hline 6. Otras transacciones & $351,883,892,896,911,931,941,961,971$. \\
\hline
\end{tabular}

Fuente: J. Durán Lima y M. Álvarez, "Manual de comercio exterior y política comercial: nociones básicas, clasificaciones e indicadores de posición y dinamismo", Documentos de Proyecto (LC/W.430), Santiago, Comisión Económica para América Latina y el Caribe (CEPAL), 2011.

A continuación se esquematizan y resumen los procedimientos en torno a las clasificaciones y correspondencias que se utilizaron en esta investigación:

SAC (ocho dígitos) $\rightarrow$ SAC (seis dígitos) $\rightarrow$ SA 1988/92 (seis dígitos) $\rightarrow$ CUCl Rev. 2 (tres dígitos) $\rightarrow$ Cuadro de la CEPAL (intensidad tecnológica).

Al final, los 5.017 códigos de productos de la clasificación SA 1988/92 se distribuyen de acuerdo con su intensidad tecnológica de la manera que se indica en el cuadro 2.

Cuadro 2

Distribución de los códigos de seis dígitos del Sistema Armonizado de Designación y Codificación de Mercancías 1988/92 de acuerdo con su intensidad tecnológica

(En número de productos)

\begin{tabular}{lc}
\hline \multicolumn{1}{c}{ Categorías y grupos } & \\
\hline Bienes primarios & 619 \\
\hline Manufacturas basadas en recursos naturales & 1191 \\
\hline Productos industrializados agrícolas o forestales & 476 \\
\hline Otros productos basados en recursos naturales & 715 \\
\hline Manufacturas de baja tecnología & 1416 \\
\hline Productos textiles y de moda & 737 \\
\hline Otros productos de baja tecnología & 679 \\
\hline Manufacturas de tecnología media & 1356 \\
\hline Productos automotrices & 61 \\
\hline Industrias de procesos de tecnología media & 615 \\
\hline Industrias de ingeniería de tecnología media & 680 \\
\hline Manufacturas de alta tecnología & 398 \\
\hline Productos eléctricos y electrónicos & 205 \\
\hline Otros productos de alta tecnología & 193 \\
\hline Otras transacciones & 37 \\
\hline Total & 5017 \\
\hline
\end{tabular}

Fuente: Elaboración propia, sobre la base de Solución Comercial Integrada Mundial (WITS), 9 de septiembre de 2016 [en línea] https://wits.worldbank.org/default.aspx?lang=es; y J. Durán Lima y M. Álvarez, "Manual de comercio exterior y política comercial: nociones básicas, clasificaciones e indicadores de posición y dinamismo", Documentos de Proyecto (LC/W.430), Santiago, Comisión Económica para América Latina y el Caribe (CEPAL), 2011.

Como indicadores comerciales generales se utilizan la balanza comercial, el cociente de las exportaciones y las importaciones, la participación de las exportaciones en el total del país y la participación del comercio con los Estados Unidos y Centroamérica en el total de las transacciones comerciales de El Salvador.

Los indicadores de diversificación utilizados son el número de productos exportados y la participación de las exportaciones según la intensidad tecnológica incorporada. Con el objetivo de obtener resultados robustos se utilizan dos indicadores de concentración que permiten calcular el nivel de diversificación de la cesta exportadora de El Salvador hacia Centroamérica y los Estados Unidos: el 
índice de Herfindahl-Hirschman (IHH) normalizado y el índice de Theil (IT). En ambos índices se usa la nomenclatura de seis dígitos del SA 1988/92 y se agrupan los productos de acuerdo con el cuadro de intensidad tecnológica (véase el cuadro 1).

Se estudia el período transcurrido entre 2005 y 2015, examinando de manera puntual los años 2005 y 2015, así como el total del comercio con los Estados Unidos y Centroamérica entre esos años. Se eligió este período de estudio considerando que 2015 es el último dato definitivo disponible y debido a que, desde 2005, en las estadísticas nacionales de El Salvador los datos del comercio internacional de la maquila se desagregan por destino $u$ origen y por producto.

El indicador de concentración $I H H$ se calcula de la siguiente manera:

$$
I H H_{j}=\sum\left(\frac{x_{i j}}{\sum x_{i j}}\right)^{2}
$$

donde $\mathrm{IHH}_{j}$ es el índice de Herfindahl-Hirschman del grupo de bienes $j$, que puede estar integrado por todos los bienes o por un grupo de ellos, $X_{i j}$ equivale al bien $i$ que pertenece a $j$.

Con el fin de comparar los resultados, este índice se normaliza de la siguiente manera:

$$
I H H n_{j}=\left(\frac{I H H_{j}-1 / n_{j}}{1-^{-1} / n_{j}}\right) * 100
$$

donde $\mathrm{IHH}_{j}$ es el índice de Herfindahl-Hirschman normalizado del grupo de bienes $j$ y $n_{j}$ es el número de productos que integran $j$.

El rango de valores que arroja el cálculo del $I H H$ va de 0 a 100 y, para interpretarlos, se utiliza la escala que proponen Durán Lima y Álvarez (2011):

- Mayor de 18: concentración

- $\quad$ Entre 10 y 18: concentración moderada

- $\quad$ Entre 0 y 10: diversificación

El indicador de concentración de Theil (IT) se calcula de la siguiente manera:

$$
I T_{j}=\frac{1}{n_{j}} \sum_{i=1}^{n_{j}}\left[\frac{x_{i j}}{P_{j}} *\left(\ln \frac{x_{i j}}{P_{j}}\right)\right]
$$

donde $I T_{j}$ es el índice de Theil del grupo de bienes $j, x_{i j}$ es el bien i que pertenece a $j, n_{j}$ es el número de productos de $j$ y $P_{j}=\frac{\sum_{i=1}^{n_{j}} x_{i j}}{n_{j}}$, es decir, el promedio del monto de exportación de cada uno de los bienes del grupo $j$. El rango de valores del $I T$ varía de acuerdo al número de productos, desde 0 hasta In $n_{j}$. Por lo tanto, con el objetivo de comparar los resultados, el IT se calculará por medio de la siguiente fórmula:

$$
I T_{j}=\left\{\frac{\frac{1}{n_{j}} \sum_{i=1}^{n_{j}}\left[\frac{x_{i j}}{P_{j}} *\left(\ln \frac{x_{i j}}{P_{j}}\right)\right]}{\ln n_{j}}\right\} * 100
$$

donde las variables tienen los valores que se indicaron respecto a la fórmula (3).

Al implementar la fórmula (4), el rango de valores del $I T$ va de 0 a 100 . Durán Lima y Álvarez (2011) utilizan la fórmula (3) y sugieren que, en el caso de la CUCl Rev. 2 de 5 dígitos 
(1.777 códigos de productos), los valores superiores a 4 se tipifiquen como concentración y los inferiores a 2,5 como diversificación. Por lo tanto, se utiliza este caso para generar una tipología de la siguiente manera: $\left(\frac{4}{\ln 1.777}\right) * 100 \approx 53 ;\left(\frac{2,5}{\ln 1.777}\right) * 100 \approx 33$, y se utiliza la siguiente escala para interpretar los resultados:

- Mayor de 53: concentración

- $\quad$ Entre 33 y 53: concentración moderada

- $\quad$ Entre 0 y 33: diversificación

Tal como se puede observar en las fórmulas (3) y (4), en el caso de que $x_{i j}$ fuera igual a 0 , el cálculo del $I T$ se encontraría indeterminado. Por ello, se aplica la ley matemática de L'Hôpital:

$$
\lim _{x_{i j} \rightarrow 0}\left(\ln \frac{x_{i j}}{P}\right)=0
$$

Cadot, Carrère y Strauss-Kahn (2011) señalan que una de las ventajas de usar el índice de Theil es que se puede descomponer en dos partes: una correspondiente al grado de diversificación entre grupos (intergrupos), y otra que contiene el grado de diversificación en el interior de cada grupo (intragrupos). Ello es útil porque nos permite saber si la diversificación o la concentración proviene del interior de los grupos analizados o de entre ellos.

En la presente investigación se realiza esta descomposición respecto de los 5.017 productos $\left(I T^{\top}\right)$, tomando en cuenta la existencia de 11 grupos $j$ de acuerdo con la intensidad tecnológica incorporada (véase el cuadro 1). La descomposición del IT se realizó de la siguiente manera:

$$
\begin{gathered}
I T^{T}=I T^{W}+I T^{B} \\
I T^{W}=\sum_{j=1}^{j} s^{j} I T_{j} \\
I T^{B}=\sum_{j=1}^{j} s^{j}\left(\ln \frac{P_{j}}{P}\right)
\end{gathered}
$$

donde $I T^{T}$ es el índice de Theil de los 5.017 productos analizados, $I T^{W}$ es el índice de Theil intragrupos, $I T^{B}$ es el índice de Theil intergrupos, $s^{j}$ es la participación del monto de las exportaciones de $j$ en el total de las exportaciones, $I T_{j}$ es el índice de Theil de $j, P_{j}$ es el promedio del monto de exportación de cada uno de los bienes de $j$ y $P$ es el promedio del monto de exportación de cada uno de los 5.017 productos analizados.

Descomponer el índice de Theil es relevante para la interpretación de los resultados, ya que el $I T$ intragrupos se vincula con la diversificación relacionada y el $I T$ intergrupos con la diversificación no relacionada.

\section{Resultados}

En el presente apartado se comparan los resultados que se obtienen al calcular la diversificación de las exportaciones de El Salvador hacia Centroamérica y hacia los Estados Unidos. En calidad de antecedentes, en el gráfico 1 se presenta una comparación de algunos indicadores comerciales relevantes. Desde 2005, en las relaciones comerciales de El Salvador con Centroamérica se ha mantenido un virtual equilibrio comercial, mientras que, en las del país con los Estados Unidos, se ha presentado un déficit comercial creciente que coincide con la tendencia que se ha mantenido en las relaciones con el mundo en su conjunto (véanse los gráficos 1A y 1B). Lo anterior es síntoma de la 
pérdida constante de competitividad que ha sufrido el aparato exportador salvadoreño. El Salvador ha logrado financiar este déficit comercial creciente gracias al aporte de las remesas familiares, de la inversión extranjera directa y de la deuda externa ${ }^{6}$.

\section{Gráfico 1}

El Salvador: indicadores del comercio con los Estados Unidos y Centroamérica, 2005-2015

A. Balanza comercial

(en millones de dólares corrientes)

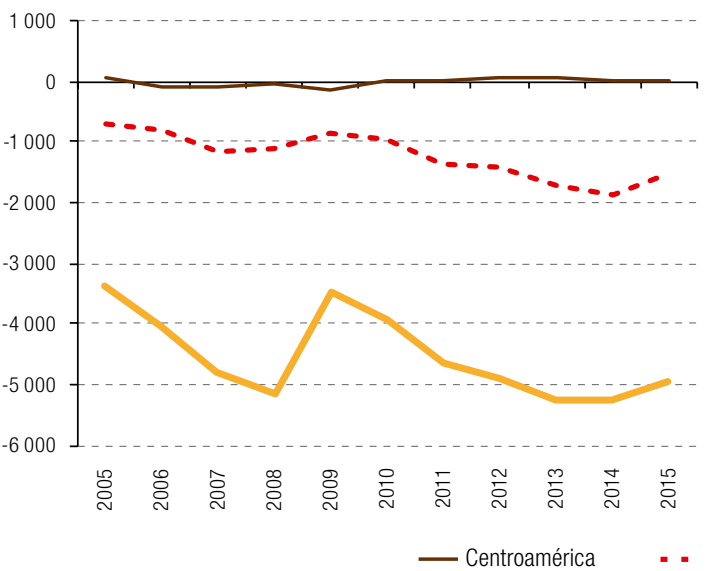

C. Participación de las exportaciones hacia los Estados Unidos y Centroamérica en el total de las exportaciones del país (en porcentajes)

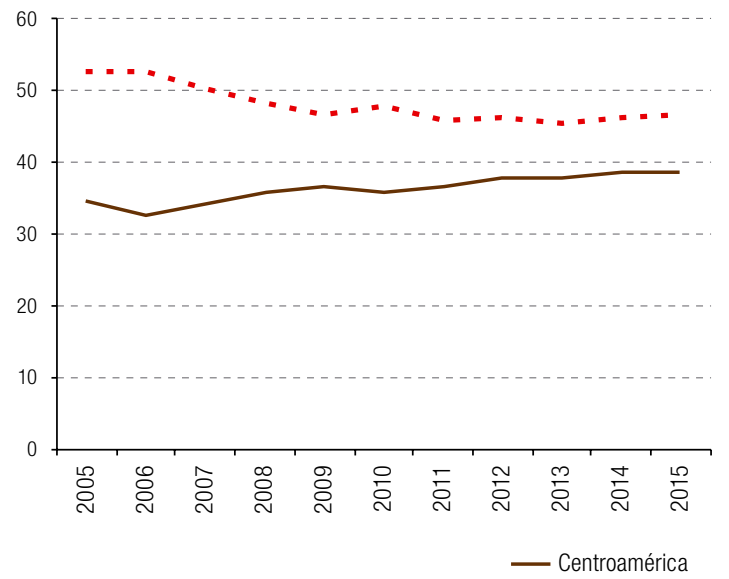

B. Cociente de las exportaciones y las importaciones (en porcentajes)

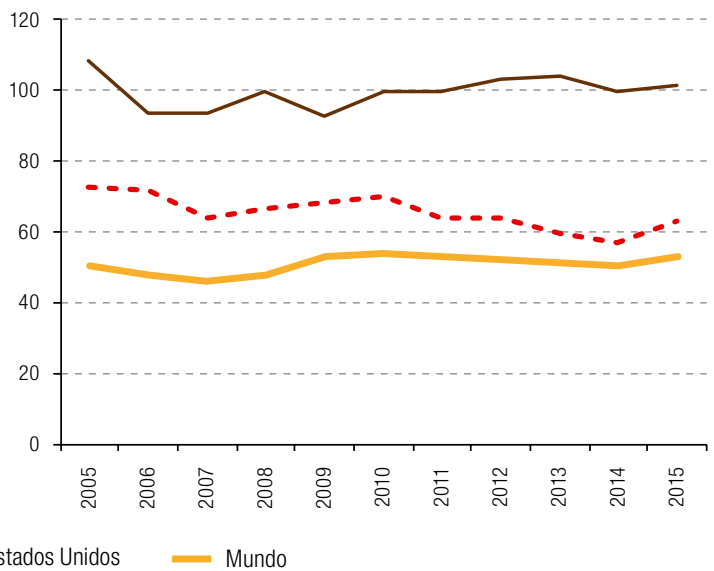

D. Participación del comercio (exportaciones e importaciones) con los Estados Unidos y Centroamérica en el total del comercio del país (en porcentajes)

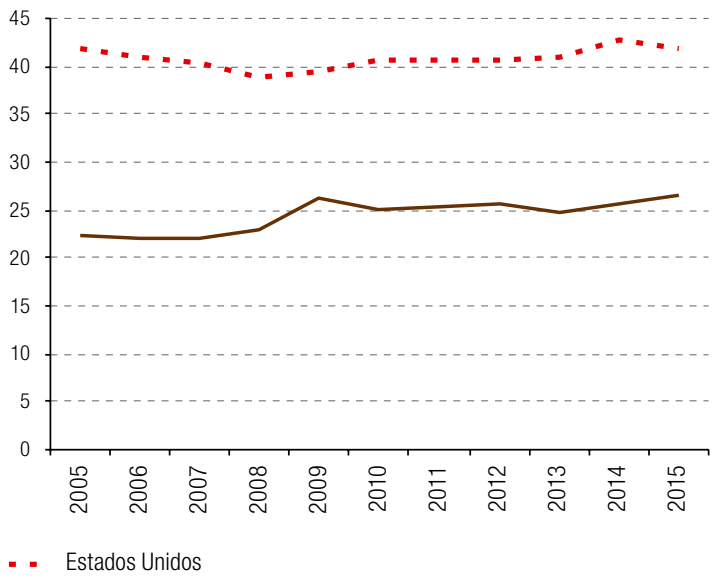

Fuente: Elaboración propia, sobre la base de información de la base de datos Comercio Exterior del Banco Central de Reserva de El Salvador.

Nota: El cociente de las exportaciones y las importaciones indica superávit comercial cuando es superior al 100\% (equilibrio) y déficit comercial cuando es inferior a ese valor.

Al realizar un balance de los datos reflejados en los gráficos 1C y 1D, se observa que el peso del comercio con los Estados Unidos es superior al del comercio con Centroamérica. Entre 2005 y 2015, el primero representó el 40,89\% del total, mientras que el segundo representó el 24,58\%. En términos

6 Según la base de datos del Banco Central de Reserva de El Salvador, las remesas familiares cubrieron el 82,51\% del total del déficit comercial entre 2005 y 2015. 
de las exportaciones del período, el $36,51 \%$ se dirigieron hacia Centroamérica, mientras que el $47,71 \%$ tuvieron como destino los Estados Unidos. Si se excluye la maquila, Centroamérica pasa a ser el principal destino de las exportaciones de El Salvador, con el 47,47\%, y los Estados Unidos es el segundo destino principal, con el 32,36\%. Esto indica que, a pesar de la implementación del Tratado de Libre Comercio entre República Dominicana, Centroamérica y los Estados Unidos, las exportaciones siguen siendo en su mayoría pertenecientes al esquema de la maquila, mientras que el principal motor del aparato exportador no maquilador de El Salvador es el comercio intrarregional.

Depender en gran medida de la maquila da lugar a la formación de una economía dual en el interior del país. Dicha economía se caracteriza por un incremento de la productividad laboral en las zonas francas, que es incapaz de arrastrar al resto de la economía (Ugarteche, 1997). Al respecto, Pérez-Caldentey y Vernengo (2008) sostienen que el problema de los países con economía dual es que exportan mano de obra barata, ya sea de manera directa, por medio de la inmigración, o indirecta, a través de los regímenes de zonas francas. Según Vernengo (2015), lo anterior genera problemas similares a los que tienen las economías sudamericanas con las exportaciones de materias primas, es decir, crisis recurrentes de la balanza de pagos debido a que no es posible financiar las importaciones con las exportaciones en el largo plazo.

Beteta y Moreno-Brid (2014) señalan que, en el caso de los países de Centroamérica, la inserción en las cadenas mundiales de valor se produce principalmente mediante la industria maquiladora y las zonas francas de procesamiento para la exportación. Debido a ello, el dinamismo de la inversión extranjera directa en las zonas francas se contrarresta con el flujo neto de capitales y las remisiones al exterior por concepto de utilidades y regalías. En el caso particular de El Salvador, Vega, Morales y Ayala (2012) argumentan que las maquilas poseen escasos eslabonamientos con la economía local, operan en su mayoría en el sector textil, gozan de exenciones impositivas y expatrian sus ganancias.

En cuanto al número de productos exportados, en el cuadro 3 se observa que, en todas las categorías de bienes clasificados por su contenido tecnológico (a excepción de "otras transacciones" en 2015 y 2005-2015), el número de productos exportados hacia Centroamérica es mayor que el de los exportados hacia los Estados Unidos. Esto permite inferir la presencia de un mayor número de empresas exportadoras, ya que en la literatura sobre el comercio intracentroamericano se sostiene que la mayor parte de las empresas que operan en el comercio intrarregional son pymes (véase Castillo, Aguilera y García, 2013; Caldentey del Pozo, 2010; Schatan y otros, 2008). Por lo tanto, en el marco del contexto de la integración centroamericana Sur-Sur, las transacciones comerciales intrarregionales tienen un mayor potencial de promover encadenamientos locales que fortalecen la economía interna. Por el contrario, las transacciones comerciales con los Estados Unidos solo profundizan la existencia de una economía dual en la que el relego de la estructura productiva local con respecto a la industria maquiladora es cada vez mayor.

La tasa de crecimiento del número de productos exportados entre 2005 y 2015 es mayor en el comercio con los Estados Unidos (16,5\%) que en el comercio con Centroamérica $(5,11 \%)$. No obstante, este crecimiento es insuficiente, ya que, en 2015, El Salvador apenas exportó el 21,11\% del número máximo de productos exportables hacia los Estados Unidos ${ }^{7}$, dato que contrasta con el 47,58\% registrado en las transacciones con Centroamérica. Aun así, la diversidad de los productos exportados, ya sea hacia los Estados Unidos o hacia Centroamérica, es muy baja si se la compara con el número de productos exportados desde Guatemala hacia estos mismos destinos. Guatemala exporta un 5,56\% más hacia los Estados Unidos y un 10,76\% más hacia Centroamérica en relación con el número máximo de productos exportables ${ }^{8}$.

\footnotetext{
7 El número máximo de productos exportables es 5.017, es decir, los 5.017 códigos del Sistema Armonizado de Designación y Codificación de Mercancías 1988/92 a un nivel de desagregación de seis dígitos.

8 Para realizar este cálculo se utilizó información estadística de las exportaciones de Guatemala obtenida de la Base de Datos de las Naciones Unidas sobre Estadísticas de Comercio de Productos Básicos (COMTRADE) (WITS, 2016).
} 


\section{Cuadro 3}

El Salvador: productos exportados hacia los Estados Unidos y Centroamérica, por grupo de intensidad tecnológica, 2005-2015

(En número de productos)

\begin{tabular}{|c|c|c|c|c|c|c|}
\hline \multirow{2}{*}{ Categorías y grupos } & \multicolumn{3}{|c|}{ Estados Unidos } & \multicolumn{3}{|c|}{ Centroamérica } \\
\hline & 2005 & 2015 & 2005-2015 & 2005 & 2015 & 2005-2015 \\
\hline Bienes primarios & 62 & 67 & 150 & 137 & 200 & 314 \\
\hline Manufacturas basadas en recursos naturales & 119 & 140 & 331 & 450 & 457 & 714 \\
\hline Productos industrializados agrícolas o forestales & 92 & 102 & 204 & 219 & 239 & 325 \\
\hline Otros productos basados en recursos naturales & 27 & 38 & 127 & 231 & 218 & 389 \\
\hline Manufacturas de baja tecnología & 415 & 471 & 791 & 784 & 782 & 1067 \\
\hline Productos textiles y de moda & 259 & 267 & 442 & 388 & 386 & 541 \\
\hline Otros productos de baja tecnología & 156 & 204 & 349 & 396 & 396 & 526 \\
\hline Manufacturas de tecnología media & 204 & 254 & 623 & 687 & 710 & 1030 \\
\hline Productos automotrices & 14 & 19 & 38 & 34 & 37 & 55 \\
\hline Industrias de procesos de tecnología media & 65 & 84 & 201 & 276 & 273 & 413 \\
\hline Industrias de ingeniería de tecnología media & 125 & 151 & 384 & 377 & 400 & 562 \\
\hline Manufacturas de alta tecnología & 92 & 103 & 233 & 190 & 215 & 303 \\
\hline Productos eléctricos y electrónicos & 62 & 59 & 131 & 114 & 124 & 160 \\
\hline Otros productos de alta tecnología & 30 & 44 & 102 & 76 & 91 & 143 \\
\hline Otras transacciones & 17 & 24 & 30 & 23 & 23 & 29 \\
\hline Total de exportaciones & 909 & 1059 & 2158 & 2271 & 2387 & 3457 \\
\hline
\end{tabular}

Fuente: Elaboración propia, sobre la base de información de la base de datos Comercio Exterior del Banco Central de Reserva de El Salvador.

Nota: Se utilizó el Sistema Armonizado de Designación y Codificación de Mercancías 1988/92 a nivel de seis dígitos, que contiene 5.017 categorías.

Otro punto que se debe destacar es la escasa sostenibilidad del patrón exportador salvadoreño. El número de productos exportados en 2015 es considerablemente inferior al que corresponde a la totalidad del período de estudio, y este hecho ocurre tanto en las transacciones con Centroamérica como en las transacciones con los Estados Unidos en particular ${ }^{9}$. Córcoles, Díaz-Mora y Gandoy (2015) señalan que la diversificación exportadora es uno de los factores que influye en la sobrevivencia de los productos exportados, cuestión que explicaría las diferencias registradas entre el comercio con los Estados Unidos y el comercio con Centroamérica. De igual manera, en varios estudios se indica que la escasa sobrevivencia de las exportaciones es una de las principales causas del mal desempeño exportador de los países en desarrollo (Besedes y Prusa, 2007; Besedes y Blyde, 2010).

En el caso de las exportaciones dirigidas hacia los Estados Unidos, el valor se concentra en las manufacturas de baja tecnología, entre las que predomina el sector textil (véase el cuadro 4). Este resultado coincide con el que obtuvieron Martínez y Cortés (2004) que, utilizando datos que iban hasta 2002, calcularon que el sector textil era la base de las exportaciones de Centroamérica hacia los Estados Unidos. El principal motivo de este comportamiento es la presencia de la industria maquiladora, que opera en su mayoría con los Estados Unidos. Por su parte, en el período 2005-2015, los productos de tecnología media y alta exportados a los Estados Unidos representaron solamente el $11,48 \%$ del total de las exportaciones hacia ese destino, mientras que, en el caso de Centroamérica, dicho porcentaje fue del 17,63\%. Esto denota la falta de intensidad tecnológica incorporada en las exportaciones salvadoreñas.

9 El número de productos exportados hacia los Estados Unidos en 2015 representó el 49,08\% del número de productos exportados a ese país en el total del período comprendido entre 2005 y 2015. En el caso de las exportaciones hacia Centroamérica, este dato aumenta al $69,05 \%$. 
Cuadro 4

El Salvador: participación de los grupos de intensidad tecnológica en las exportaciones hacia los Estados Unidos y Centroamérica, 2005-2015

(En porcentajes)

\begin{tabular}{|c|c|c|c|c|c|c|}
\hline \multirow{2}{*}{ Categorías y grupos } & \multicolumn{3}{|c|}{ Estados Unidos } & \multicolumn{3}{|c|}{ Centroamérica } \\
\hline & 2005 & 2015 & $2005-2015$ & 2005 & 2015 & 2005-2015 \\
\hline Bienes primarios & 4,12 & 3,94 & 5,06 & 2,15 & 2,94 & 3,07 \\
\hline Manufacturas basadas en recursos naturales & 4,14 & 7,22 & 6,78 & 24,21 & 26,47 & 27,86 \\
\hline Productos industrializados agrícolas o forestales & 3,24 & 5,35 & 5,07 & 17,78 & 20,77 & 20,94 \\
\hline Otros productos basados en recursos naturales & 0,90 & 1,87 & 1,71 & 6,43 & 5,70 & 6,92 \\
\hline Manufacturas de baja tecnología & 82,30 & 79,82 & 74,86 & 53,17 & 51,52 & 49,18 \\
\hline Productos textiles y de moda & 80,82 & 78,26 & 73,56 & 26,52 & 22,12 & 20,05 \\
\hline Otros productos de baja tecnología & 1,48 & 1,56 & 1,30 & 26,65 & 29,41 & 29,13 \\
\hline Manufacturas de tecnología media & 2,26 & 2,00 & 4,12 & 12,82 & 12,20 & 12,16 \\
\hline Productos automotrices & 0,01 & 0,07 & 0,08 & 0,50 & 0,19 & 0,23 \\
\hline Industrias de procesos de tecnología media & 2,00 & 0,29 & 3,35 & 9,26 & 10,14 & 9,84 \\
\hline Industrias de ingeniería de tecnología media & 0,25 & 1,63 & 0,70 & 3,06 & 1,87 & 2,09 \\
\hline Manufacturas de alta tecnología & 6,91 & 6,42 & 7,36 & 6,10 & 5,22 & 5,47 \\
\hline Productos eléctricos y electrónicos & 6,85 & 6,33 & 7,28 & 1,32 & 0,92 & 1,16 \\
\hline Otros productos de alta tecnología & 0,06 & 0,09 & 0,08 & 4,79 & 4,30 & 4,31 \\
\hline Otras transacciones & 0,26 & 0,60 & 1,82 & 1,54 & 1,64 & 2,25 \\
\hline Total de exportaciones & 100 & 100 & 100 & 100 & 100 & 100 \\
\hline
\end{tabular}

Fuente: Elaboración propia, sobre la base de información de la base de datos Comercio Exterior del Banco Central de Reserva de El Salvador.

Nota: Se utilizó el Sistema Armonizado de Designación y Codificación de Mercancías 1988/92 a nivel de seis dígitos, que contiene 5.017 categorías.

Las características del comercio intrarregional de El Salvador, en oposición a las de sus intercambios con los Estados Unidos, son las siguientes: mayor diversidad y peso de los productos de tecnología media y alta en el total de los productos exportados, presencia de pymes y mejor sobrevivencia de las ventas al exterior. Esto apunta en dirección a que el comercio intrarregional es un escenario más conveniente para desarrollar las capacidades productivas y tecnológicas que permitan escalar en los roles exportadores de las cadenas mundiales de valor.

En este sentido, la distribución de las exportaciones de acuerdo con el monto monetario también ha sido menos concentrada en las transacciones con Centroamérica, y la categoría con mayor predominio ha sido la que corresponde a las manufacturas de baja tecnología. No obstante, en el caso de las exportaciones intrarregionales de El Salvador, la participación de los productos textiles y de moda se reduce de manera considerable, lo que sugiere la existencia de una distribución más diversificada en lo que respecta a los montos exportados. Una explicación de este fenómeno es la baja presencia de la industria maquiladora textil en el comercio intrarregional.

En términos comparativos, la estructura de los montos de exportación de acuerdo con la intensidad tecnológica incorporada en los productos exportados hacia los Estados Unidos en 2015 es similar a la de 2005 (véase el cuadro 4). Lo anterior se puede explicar por dos factores. El primero es el predominio del sector textil, promovido por la Ley del Régimen de Zonas Francas y Recintos Fiscales de El Salvador, que entró en vigencia en septiembre de 1998, fecha anterior a la entrada en vigencia del Tratado de Libre Comercio entre República Dominicana, Centroamérica y los Estados Unidos. El segundo tiene que ver con los escasos derrames tecnológicos ocurridos durante el período de estudio como producto de las exportaciones de El Salvador hacia los Estados Unidos, a causa de lo 
cual la estructura de los montos de exportación casi no se modificó. Es preciso mencionar que las transferencias de conocimiento mediante derrames tecnológicos, que son un efecto esperado de la integración Norte-Sur (Schiff, Wang y Olarreaga, 2002), no han ocurrido en el caso de las relaciones comerciales entre el Salvador y los Estados Unidos ${ }^{10}$.

En el cuadro 5 se mide la concentración de las exportaciones en 2005 y 2015 por medio del $I H H$ y el $I T^{11}$. A pesar de que hay diferencias notables en las magnitudes, se puede observar que, en los dos años, ambos indicadores confirman la existencia de un patrón exportador concentrado en la mayoría de las categorías y los grupos de productos que se exportan hacia los Estados Unidos. En el caso de las exportaciones hacia Centroamérica, aunque el patrón exportador es moderadamente concentrado, su grado de diversificación es mayor en términos relativos cuando se interpretan los datos que arroja el $I T$.

\section{Cuadro 5}

El Salvador: indicadores de diversificación de las exportaciones hacia los Estados Unidos y Centroamérica, por grupo de intensidad tecnológica, 2005 y 2015

\begin{tabular}{|c|c|c|c|c|c|c|c|c|}
\hline \multirow[b]{3}{*}{ Categorías y grupos } & \multicolumn{8}{|c|}{2005} \\
\hline & \multicolumn{4}{|c|}{ Estados Unidos } & \multicolumn{4}{|c|}{ Centroamérica } \\
\hline & IHH & $\begin{array}{c}\text { Tipología } \\
\text { IHH }\end{array}$ & IT & $\begin{array}{l}\text { Tipología } \\
\qquad I T\end{array}$ & $\mathrm{IHH}$ & $\begin{array}{c}\text { Tipología } \\
\text { IHH }\end{array}$ & IT & $\begin{array}{l}\text { Tipología } \\
\qquad I T\end{array}$ \\
\hline Bienes primarios & 47,74 & C & 78,61 & C & 9,15 & D & 54,24 & C \\
\hline $\begin{array}{l}\text { Manufacturas basadas en } \\
\text { recursos naturales }\end{array}$ & 20,23 & C & 68,91 & C & 4,89 & $\mathrm{D}$ & 49,54 & CM \\
\hline $\begin{array}{l}\text { Productos industrializados } \\
\text { agrícolas o forestales }\end{array}$ & 28,13 & C & 68,53 & C & 6,67 & D & 48,35 & CM \\
\hline $\begin{array}{l}\text { Otros productos basados } \\
\text { en recursos naturales }\end{array}$ & 62,74 & C & 88,78 & C & 17,81 & CM & 62,41 & C \\
\hline Manufacturas de baja tecnología & 11,52 & $\mathrm{CM}$ & 56,51 & C & 7,99 & D & 47,86 & $\mathrm{CM}$ \\
\hline Productos textiles y de moda & 11,89 & CM & 53,46 & C & 27,36 & C & 62,46 & C \\
\hline Otros productos de baja tecnología & 10,55 & $\mathrm{CM}$ & 58,81 & C & 4,73 & D & 43,28 & $\mathrm{CM}$ \\
\hline Manufacturas de tecnología media & 53,15 & C & 79,93 & C & 4,69 & D & 41,21 & $\mathrm{CM}$ \\
\hline Productos automotrices & 23,13 & C & 57,32 & C & 52,49 & C & 70,23 & C \\
\hline $\begin{array}{l}\text { Industrias de procesos } \\
\text { de tecnología media }\end{array}$ & 24,27 & C & 87,73 & C & 53,20 & C & 45,00 & $\mathrm{CM}$ \\
\hline $\begin{array}{l}\text { Industrias de ingeniería } \\
\text { de tecnología media }\end{array}$ & 27,38 & C & 51,33 & CM & 5,16 & D & 39,81 & $\mathrm{CM}$ \\
\hline Manufacturas de alta tecnología & 39,48 & C & 80,38 & C & 26,45 & C & 65,21 & C \\
\hline Productos eléctricos y electrónicos & 40,07 & $\mathrm{C}$ & 79,06 & C & 19,86 & C & 53,45 & C \\
\hline Otros productos de alta tecnología & 18,02 & C & 62,44 & C & 41,44 & C & 75,12 & C \\
\hline Otras transacciones & 41,79 & C & 66,60 & C & 19,72 & C & 47,01 & $\mathrm{CM}$ \\
\hline Total de exportaciones & 8,16 & D & 58,08 & C & 2,74 & D & 42,49 & $\mathrm{CM}$ \\
\hline
\end{tabular}

\footnotetext{
10 Según la teoría ortodoxa del comercio internacional, la integración Norte-Sur promueve los derrames tecnológicos mediante la importación de bienes de capital. En El Salvador, según la base de datos comerciales COMTRADE consultada en la WITS (2016), las importaciones de bienes de capital provenientes de los Estados Unidos se redujeron del 20,53\% del total del monto importado en 2005 al 15,30\% en 2015. En ese período, dichas importaciones decrecieron todos los años, con excepción de 2006, 2009 y 2015. La tasa de decrecimiento promedio anual fue del 2,13\% durante el período de estudio, y 2008 y 2010 fueron los años que presentaron las tasas más altas: el 17,44\% y el 10,60\%, respectivamente.

${ }^{11}$ El $I H H$ tiende a sobreestimarse cuando se lo calcula en relación con un número amplio de productos. Por lo tanto, al analizar la diversificación de todos los productos exportados se dará preferencia a los valores que arroje el IT.
} 
Cuadro 5 (conclusión)

\begin{tabular}{|c|c|c|c|c|c|c|c|c|}
\hline \multirow[b]{3}{*}{ Categorías y grupos } & \multicolumn{8}{|c|}{2015} \\
\hline & \multicolumn{4}{|c|}{ Estados Unidos } & \multicolumn{4}{|c|}{ Centroamérica } \\
\hline & $\mathrm{IHH}$ & $\begin{array}{c}\text { Tipología } \\
\text { IHH }\end{array}$ & IT & $\begin{array}{c}\text { Tipología } \\
\text { IT }\end{array}$ & $\mathrm{IHH}$ & $\begin{array}{c}\text { Tipología } \\
\text { IT }\end{array}$ & IT & $\begin{array}{c}\text { Tipología } \\
\text { IT }\end{array}$ \\
\hline Bienes primarios & 49,12 & C & 79,18 & C & 7,75 & D & 54,82 & C \\
\hline $\begin{array}{l}\text { Manufacturas basadas en } \\
\text { recursos naturales }\end{array}$ & 10,46 & $\mathrm{CM}$ & 60,93 & C & 4,91 & D & 49,12 & $\mathrm{CM}$ \\
\hline $\begin{array}{l}\text { Productos industrializados } \\
\text { agrícolas o forestales }\end{array}$ & 15,32 & $\mathrm{CM}$ & 60,06 & C & 6,31 & $\mathrm{D}$ & 47,40 & $\mathrm{CM}$ \\
\hline $\begin{array}{l}\text { Otros productos basados } \\
\text { en recursos naturales }\end{array}$ & 30,14 & C & 78,23 & C & 21,02 & C & 61,96 & C \\
\hline Manufacturas de baja tecnología & 10,34 & $\mathrm{CM}$ & 56,52 & C & 3,31 & D & 43,51 & $\mathrm{CM}$ \\
\hline Productos textiles y de moda & 10,70 & $\mathrm{CM}$ & 53,69 & C & 7,43 & D & 50,94 & $\mathrm{CM}$ \\
\hline Otros productos de baja tecnología & 6,48 & $\mathrm{D}$ & 52,64 & $\mathrm{CM}$ & 5,97 & D & 45,58 & $\mathrm{CM}$ \\
\hline Manufacturas de tecnología media & 51,36 & C & 76,47 & C & 3,21 & D & 41,56 & CM \\
\hline Productos automotrices & 41,08 & C & 71,26 & C & 9,71 & $\mathrm{D}$ & 37,44 & $\mathrm{CM}$ \\
\hline $\begin{array}{l}\text { Industrias de procesos } \\
\text { de tecnología media }\end{array}$ & 41,96 & C & 55,57 & C & 11,05 & CM & 42,96 & CM \\
\hline $\begin{array}{l}\text { Industrias de ingeniería } \\
\text { de tecnología media }\end{array}$ & 76,53 & C & 87,44 & C & 4,39 & D & 37,61 & $\mathrm{CM}$ \\
\hline Manufacturas de alta tecnología & 62,25 & C & 85,81 & C & 29,95 & C & 65,70 & C \\
\hline Productos eléctricos y electrónicos & 63,99 & $\mathrm{C}$ & 85,89 & $\mathrm{C}$ & 9,51 & $\mathrm{D}$ & 44,86 & $\mathrm{CM}$ \\
\hline Otros productos de alta tecnología & 12,69 & $\mathrm{CM}$ & 54,88 & C & 43,72 & C & 75,36 & C \\
\hline Otras transacciones & 54,61 & $C$ & 75,57 & C & 17,21 & $\mathrm{CM}$ & 45,62 & $\mathrm{CM}$ \\
\hline Total de exportaciones & 7,02 & D & 64,84 & C & 1,37 & $\mathrm{D}$ & 45,77 & $\mathrm{CM}$ \\
\hline
\end{tabular}

Fuente: Elaboración propia, sobre la base de información de la base de datos Comercio Exterior del Banco Central de Reserva de El Salvador.

Nota: Se utilizó el Sistema Armonizado de Designación y Codificación de Mercancías 1988/92 a nivel de seis dígitos, que contiene 5.017 categorías. IHH es el índice de Herfindahl-Hirschman normalizado, IT es el índice de Theil, C significa concentración, CM significa concentración moderada y D es diversificación.

Tomando en cuenta los valores del $I H H$ y del IT, en 2005 había tres grupos de productos cuyas exportaciones hacia los Estados Unidos exhibían un mayor grado de diversificación: los productos textiles y de moda, los productos automotrices y los otros productos de alta tecnología. En 2015, por otra parte, solo el grupo de otros productos de alta tecnología mostró un nivel de diversificación superior con respecto a Centroamérica. Cabe señalar, sin embargo, la reducida participación de este grupo de productos en las exportaciones totales del país ${ }^{12}$. Lo anterior confirma que el perfil exportador hacia los Estados Unidos tiene escaso dinamismo y se basa en ventajas comparativas estáticas, como la abundancia de mano de obra poco calificada.

Entre 2005 y 2015 hubo una pérdida de diversificación exportadora a nivel de todos los productos, que fue mayor en las transacciones con los Estados Unidos que en las transacciones con Centroamérica (véase el cuadro 6). No obstante, hubo mejoras en la diversificación de algunas categorías y grupos de productos. Tomando en cuenta los niveles del $I H H$ y el $I T$, en el caso del comercio con los Estados Unidos se mejoró la diversificación en dos categorías y cinco grupos de productos, mientras que, en el caso del comercio intrarregional, la diversificación mejoró en dos categorías y siete grupos de productos. Sin embargo, en las exportaciones hacia Centroamérica, el aumento del grado de diversificación fue superior en los grupos de tecnología alta o media, y, en las dirigidas hacia los Estados Unidos, dicho aumento fue superior en los grupos de baja tecnología o en las manufacturas basadas en recursos naturales ${ }^{13}$.

\footnotetext{
12 Según el cuadro 4, la participación de los otros productos de alta tecnología en las exportaciones apenas alcanzó el 0,08\% entre 2005 y 2015.

${ }^{13}$ En el caso del comercio con los Estados Unidos, el nivel de diversificación solo se incrementó en un grupo de tecnología alta o media (otros productos de alta tecnología), mientras que, en el caso del comercio con Centroamérica, dicho nivel aumentó en cuatro grupos (todos los de tecnología media y los productos eléctricos y electrónicos).
} 


\section{Cuadro 6}

El Salvador: diferencia entre los indicadores de diversificación de 2005 y 2015, correspondientes a las exportaciones hacia los Estados Unidos

y Centroamérica, por grupo de intensidad tecnológica

\begin{tabular}{|c|c|c|c|c|}
\hline \multirow{2}{*}{ Categorías y grupos } & \multicolumn{2}{|c|}{ Estados Unidos } & \multicolumn{2}{|c|}{ Centroamérica } \\
\hline & IHH & IT & IHH & IT \\
\hline Bienes primarios & 1,38 & 0,57 & $-1,41$ & 0,58 \\
\hline Manufacturas basadas en recursos naturales & $-9,77$ & $-7,98$ & 0,02 & $-0,42$ \\
\hline Productos industrializados agrícolas o forestales & $-12,81$ & $-8,47$ & $-0,36$ & $-0,94$ \\
\hline Otros productos basados en recursos naturales & $-32,59$ & $-10,56$ & 3,20 & $-0,45$ \\
\hline Manufacturas de baja tecnología & $-1,19$ & 0,02 & $-4,68$ & $-4,35$ \\
\hline Productos textiles y de moda & $-1,20$ & 0,23 & $-19,93$ & $-11,51$ \\
\hline Otros productos de baja tecnología & $-4,07$ & $-6,17$ & 1,23 & 2,31 \\
\hline Manufacturas de tecnología media & $-1,79$ & $-3,46$ & $-1,49$ & 0,35 \\
\hline Productos automotrices & 17,95 & 13,95 & $-42,78$ & $-32,80$ \\
\hline Industrias de procesos de tecnología media & 17,69 & $-32,16$ & $-42,15$ & $-2,04$ \\
\hline Industrias de ingeniería de tecnología media & 49,15 & 36,11 & $-0,77$ & $-2,19$ \\
\hline Manufacturas de alta tecnología & 22,77 & 5,43 & 3,50 & 0,48 \\
\hline Productos eléctricos y electrónicos & 23,92 & 6,83 & $-10,35$ & $-8,59$ \\
\hline Otros productos de alta tecnología & $-5,33$ & $-7,56$ & 2,28 & 0,24 \\
\hline Otras transacciones & 12,82 & 8,96 & $-2,51$ & $-1,39$ \\
\hline Total de exportaciones & $-1,14$ & 6,76 & $-1,37$ & 3,28 \\
\hline
\end{tabular}

Fuente: Elaboración propia, sobre la base de información de la base de datos Comercio Exterior del Banco Central de Reserva de El Salvador.

Nota: Se utilizó el Sistema Armonizado de Designación y Codificación de Mercancías 1988/92 a nivel de seis dígitos, que contiene 5.017 categorías. El $I H H$ es el índice de Herfindahl-Hirschman normalizado y el IT es el índice de Theil. Las diferencias se obtuvieron restando el valor del indicador de 2005 al valor del indicador de 2015. Por lo tanto, según el indicador utilizado, la diversificación de las exportaciones mejoró en las categorías y los grupos que presentan números negativos (sombreados).

En cuanto a las exportaciones de El Salvador a los Estados Unidos, los resultados demuestran una reducción de la diversificación a nivel de toda la canasta, atenuada de manera insuficiente por el incremento de la diversificación en grupos de productos con escasa intensidad tecnológica incorporada. El motivo de lo anterior es el abandono que han sufrido los sectores no maquiladores en lo que respecta a las exportaciones destinadas a los Estados Unidos. Esto ha hecho que se exporten pocos productos y en montos muy concentrados.

En contraste, a pesar de que en la política comercial salvadoreña se ha relegado la integración regional (Caldentey del Pozo, 2010), la mejora de la diversificación de la canasta exportadora entre 2005 y 2015 en el comercio intrarregional de El Salvador ocurre en grupos de tecnología media y alta. Gracias a lo anterior, las transacciones comerciales que ocurren en el marco de la integración Sur-Sur centroamericana tienen un mayor potencial para generar los efectos dinámicos de la diversificación de las exportaciones (véase Agosin, 2009). Además de presentar un mayor nivel de diversificación, el entorno regional propicia la exportación de manufacturas no ensambladas, lo que aporta un mayor valor agregado al conjunto de la economía y genera más oportunidades de crecimiento para las pymes (Schatan y otros, 2008).

De acuerdo con Samen (2010), la concentración de las exportaciones conlleva riesgos económicos y políticos. Los riesgos de carácter económico se asocian a la volatilidad e inestabilidad de las exportaciones, que afecta el nivel de ingreso por ese concepto, el crecimiento, el empleo, la inversión, la balanza comercial y la inflación, entre otros. A largo plazo también existen riesgos vinculados al deterioro de los términos de intercambio, que causa un bajo encadenamiento productivo. Desde el punto de vista político, Collier (2002) afirma que los riesgos económicos pueden conducir a la ingobernabilidad e incluso pueden ser motivo de conflictos armados. 
Con el propósito de evaluar la diversificación relacionada y la no relacionada, el IT se descompone en el $I T$ intragrupos (asociado a la primera) y el $I T$ intergrupos (asociado a la segunda). En el gráfico 2 se observa que el nivel de concentración de las exportaciones, tanto hacia Centroamérica como hacia los Estados Unidos, se explica en mayor medida por la concentración intragrupos. Lo anterior demuestra una escasa diversificación relacionada, lo que dificulta el proceso de escalamiento en las cadenas mundiales de valor por la falta de derrames tecnológicos que promuevan la difusión del conocimiento (Boschma e lammarino, 2009). Entre 2005 y 2015, la concentración medida por el IT intergrupos crece a su vez, lo que reduce la diversificación no relacionada y aumenta la vulnerabilidad ante una posible crisis dentro de un sector o sectores productivos relacionados (Essletzbichler, 2005).

Gráfico 2

El Salvador: descomposición del índice de Theil de las exportaciones hacia los Estados Unidos y Centroamérica, 2005-2015

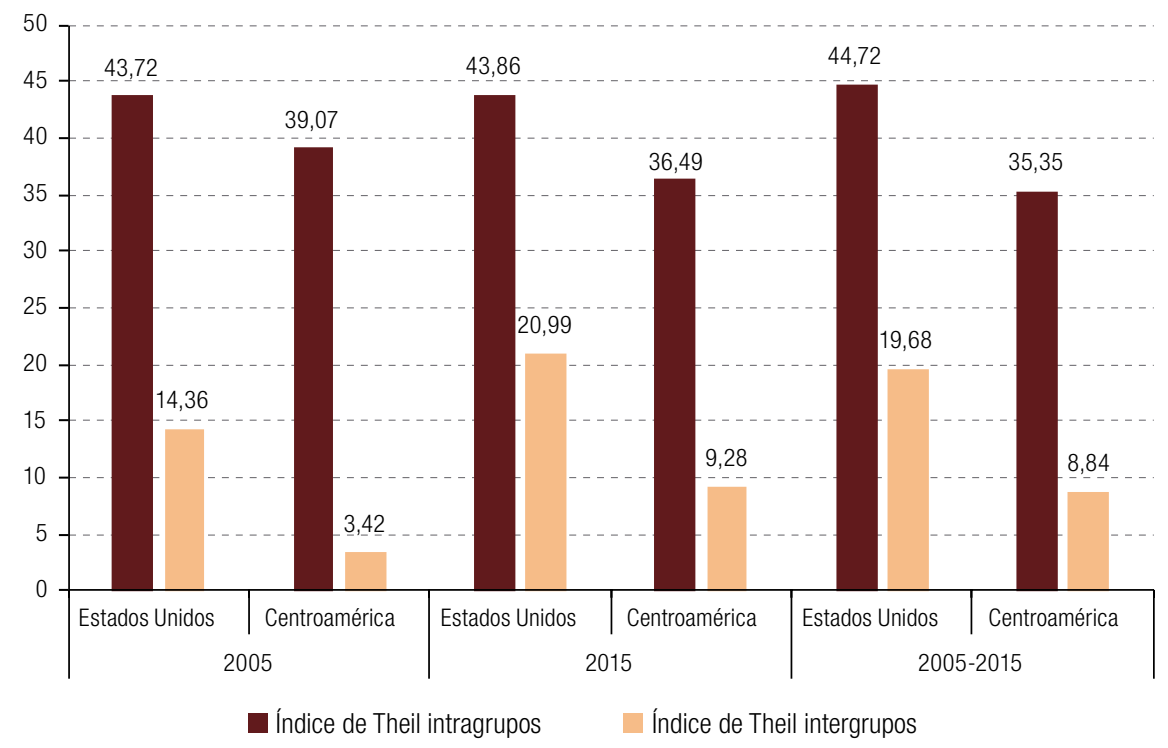

Fuente: Elaboración propia, sobre la base de información de la base de datos Comercio Exterior del Banco Central de Reserva de El Salvador.

Nota: Se utilizó el Sistema Armonizado de Designación y Codificación de Mercancías 1988/92 a nivel de seis dígitos, que contiene 5.017 categorías.

En todos los períodos analizados en el gráfico 2, la diversificación relacionada y la no relacionada es mayor en el caso de las exportaciones hacia Centroamérica. Por lo tanto, se sugiere promover la integración comercial centroamericana como mecanismo para desarrollar las capacidades productivas y tecnológicas de El Salvador mediante un mayor derrame tecnológico y un entorno macroeconómico más estable.

De acuerdo con Amaya y Cabrera (2013), El Salvador debe diversificar su canasta exportadora para lograr un mayor contenido tecnológico en las exportaciones, fortalecer los encadenamientos productivos y así alcanzar un mayor nivel de crecimiento económico sostenible en el tiempo. Además, el comercio intrarregional también se presenta como una oportunidad para contrarrestar los efectos negativos de la economía dual generada por la industria maquiladora, a fin de provocar un cambio estructural que propicie el circulo virtuoso de crecimiento que sugieren Beteta y Moreno-Brid (2014), depender menos de productos específicos y mitigar los fenómenos adversos recurrentes de los mercados internacionales. Esta oportunidad puede aprovecharse fortaleciendo el comercio intrarregional y mejorando los mecanismos de la integración económica centroamericana. 


\section{Conclusiones}

Las virtudes que presenta el comercio intrarregional según los estudios de investigación sobre Centroamérica se reflejan en el análisis empírico de este trabajo. Se ha encontrado que las transacciones comerciales de El Salvador con Centroamérica presentan niveles superiores de diversificación, sofisticación y desempeño comercial en comparación con las transacciones comerciales que el país lleva a cabo con los Estados Unidos.

Lo anterior se evidencia en el hecho de que, en el caso de las exportaciones hacia Centroamérica, el número de productos exportados es mayor, la sofisticación productiva de acuerdo al monto de las exportaciones de tecnología media y alta es más elevada, y el número de productos sofisticados es mayor. A su vez, se registra un grado superior de diversificación de las exportaciones a nivel general y en todos los grupos de contenido tecnológico, a excepción de los otros productos de alta tecnología. La razón principal por la que las exportaciones a Centroamérica son más diversas tiene que ver con las características de las empresas que participan en el comercio internacional de El Salvador. Las empresas que exportan hacia los Estados Unidos pertenecen en su mayoría al sistema de la industria maquiladora, que es operado por grandes empresas multinacionales de ese país, mientras que las que operan en el comercio intrarregional son en su mayoría pymes que tienen más encadenamientos productivos con la economía local.

En la presente investigación se ha encontrado evidencia de que, en el caso de El Salvador, es más conveniente fortalecer la integración Sur-Sur (integración centroamericana) que la integración Norte-Sur (integración con los Estados Unidos). A pesar de que es necesario hacer un estudio más detallado sobre el tema, los hallazgos apuntan en dirección a que hay más posibilidades de obtener derrames tecnológicos con la integración Sur-Sur que con la integración Norte-Sur. Esta aseveración es respaldada por el hecho de que, entre 2005 y 2015, la estructura de los montos exportados a los Estados Unidos por intensidad tecnológica fue estática, las importaciones de bienes de capital desde dicho país cayeron y las exportaciones hacia ese destino exhibieron una escasa diversificación relacionada.

En este trabajo se propone que, en el caso de El Salvador, el fortalecimiento de las relaciones comerciales con Centroamérica es un mejor mecanismo para capitalizar los efectos dinámicos de la integración comercial y la diversificación de las exportaciones. Una integración intrarregional concertada entre los países centroamericanos podría dar lugar a lo siguiente: escalamiento conjunto en las cadenas mundiales de valor; mayor participación de las pymes en el comercio internacional; diversificación de la canasta de ventas al exterior; mayor sobrevivencia de los productos exportados; fortalecimiento de los encadenamientos productivos locales; desarrollo de las capacidades tecnológicas por medio de derrames tecnológicos (mayor diversificación relacionada); reducción de la fragilidad ante las crisis que puedan generarse en un sector o sectores productivos (mayor diversificación no relacionada), y disminución de la vulnerabilidad ante los movimientos especulativos de los mercados internacionales.

Existe cierto consenso entre diferentes grupos de la sociedad salvadoreña acerca de la necesidad de diseñar una estrategia que permita diversificar las exportaciones. De hecho, ya se están dando pasos concretos en esa dirección y el mejor ejemplo es la Política Nacional de Fomento, Diversificación y Transformación Productiva de El Salvador. Existe también consenso respecto a la importancia que el comercio intrarregional y la integración económica centroamericana tienen para el desarrollo económico de El Salvador y de Centroamérica en general. No obstante, tal como señala Caldentey del Pozo (2010), los tratados bilaterales comerciales de El Salvador, en especial los de carácter Norte-Sur, como el Tratado de Libre Comercio entre República Dominicana, Centroamérica y los Estados Unidos, han relegado a un segundo plano la promoción del comercio intrarregional y la integración económica centroamericana. 
En el marco de una visión estratégica de país, la unificación de la política nacional de fomento, la diversificación y transformación productiva de El Salvador con una política comercial centrada en el comercio intrarregional, y la integración económica centroamericana podrían crear las sinergias necesarias para promover la competitividad del aparato productivo salvadoreño, aumentar las capacidades tecnológicas y generar ingresos crecientes sostenibles que en última instancia mejorarían el nivel de vida de la población.

\section{Bibliografía}

Agosin, M. (2009), "Crecimiento y diversificación de las exportaciones en economías emergentes", Revista CEPAL, № 97 (LC/G.2400-P), Santiago, Comisión Económica para América Latina y el Caribe (CEPAL).

Amaya, P. y O. Cabrera (2013), "La transformación estructural: una solución a la trampa de bajo crecimiento económico en El Salvador", Documento de Trabajo, Nㅜ 2013-01, San Salvador, Banco Central de Reserva de El Salvador.

Balassa, B. (1980), Teoría de la integración económica, Ciudad de México, Unión Tipográfica Editorial Hispano-Americana.

Bekerman, M. y C. Rikap (2010), "Integración regional y diversificación de exportaciones en el MERCOSUR: el caso de Argentina y Brasil”, Revista CEPAL, № 100 (LC/G.2442-P), Santiago, Comisión Económica para América Latina y el Caribe (CEPAL).

Bell, M. y K. Pavitt (1992), "Accumulating technological capability in developing countries", Proceedings of the World Bank Annual Conference on Development Economics, Washington, D.C., Banco Mundial.

Besedes, T. y J. Blyde (2010), "What drives export survival?: an analysis of export duration in Latin America" [en línea] http://siteresources.worldbank.org/INTRANETTRADE/Resources/Internal-Training/287823-1256848879189/ Besedes_Mar16_2010.pdf.

Besedes, T. y T. Prusa (2007), "The role of extensive and intensive margins and export growth", NBER Working Paper, № 13628, Cambridge, Massachusetts, Oficina Nacional de Investigaciones Económicas.

Beteta, H. y J. Moreno-Brid (2014), Cambio estructural y crecimiento en Centroamerica y la República Dominicana: un balance de dos décadas, 1990-2011, Libros de la CEPAL, № 122 (LC/G.2600-P), Santiago, Comisión Económica para América Latina y el Caribe (CEPAL).

Boschma, R. y S. lammarino (2009), "Related variety, trade linkages, and regional growth in Italy", Economic Geography, vol. 85, № 3.

Cadot, O., C. Carrère y V. Strauss-Kahn (2011), "Export diversification: what's behind the hump?", The Review of Economics and Statistics, vol. 93, N², Cambridge, Massachusetts, The MIT Press.

Caldentey del Pozo, P. (2010), "Panorama de la integración centroamericana: dinámica, intereses y actores", EI SICA y la UE: la integración regional en una perspectiva comparada, P. Caldentey y J. J. Romero Rodríguez (eds.), Córdoba, Fundación ETEA para el Desarrollo y la Cooperación. (2000), El desarrollo económico de Centroamérica en el marco de la integración regional, Tegucigalpa, Banco Centroamericano de Integración Económica (BCIE).

Calderón, C., D. González y C. Sanabria (2008), "Efecto exportador y tratado comercial con Estados Unidos: una evaluación coyuntural", Documento de Trabajo, N2 2008-02, San Salvador, Banco Central de Reserva de El Salvador.

Castillo, J., E. Aguilera y C. García (2013), "Centroamérica: lo impostergable de una diversificación comercial coherente", Problemas del Desarrollo, vol. 44, № 174, Ciudad de México, Universidad Nacional Autónoma de México (UNAM).

Coe, D. y E. Helpman (1995), "International R\&D spillovers", European Economic Review, vol. 39, № 5, Amsterdam, Elsevier.

Cohen Orantes, I. (1981), "El concepto de integración", Revista de la CEPAL, Nº 15 (E/CEPAL/G.1187), Santiago, Comisión Económica para América Latina y el Caribe (CEPAL).

Collier, P. (2002), "Primary commodity dependence and Africa's future", Annual Bank Conference on Development Economics, B. Pleskovic y N. Stern (eds.), Nueva York, Oxford University Press.

Córcoles, D., C. Díaz-Mora y R. Gandoy (2015), "Export survival in global value chains", World Economy, vol. $38, N^{\circ} 10$, Wiley. 
Durán Lima, J. y M. Álvarez (2011), "Manual de comercio exterior y política comercial: nociones básicas, clasificaciones e indicadores de posición y dinamismo", Documentos de Proyecto (LC/W.430), Santiago, Comisión Económica para América Latina y el Caribe (CEPAL).

Ernst, D. (2003), "Redes globales de producción, difusión de conocimiento y formación de capacidades locales: un marco conceptual", La industria electrónica en México: problemática, perspectivas y propuestas, E. Dussel, J. Palacios y G. Woo (coords.), Guadalajara, Universidad de Guadalajara.

Essletzbichler, J. (2005), "Diversity, stability and regional growth in the U.S. (1975-2002)", Papers in Evolutionary Economic Geography, № 0513, Utrecht, Universidad de Utrecht.

Frenkel, K., F. van Oort y T. Verburg (2007), "Related variety, unrelated variety and regional economic growth", Regional Studies, vol. 41, № 5, Taylor \& Francis.

Gereffi, G. (1996), "Global commodity chains: new forms of coordination and control among nations and firms in international industries", Competition and Changes, vol. 1, No 4, SAGE.

Guerra-Borges, A. (2009), "La integración centroamericana en los noventa", Fin de época: de la integración tradicional al regionalismo estratégico, A. Guerra-Borges (coord.), Ciudad de México, Siglo XXI.

Hausmann, R., J. Hwang y D. Rodrik (2007), "What you export matters", Journal of Economic Growth, vol. 12, $N^{\circ} 1$, Springer.

Lara, E. (2003), "El Salvador a trece años de políticas de ajuste y estabilización económica", Teoría y Praxis, $N^{\circ}$ 2, San Salvador, Editorial Universidad Don Bosco.

Martínez, J. y E. Cortés (2004), "Competitividad centroamericana", serie Estudios y Perspectivas, № 21 (LC/L.2153-P), Ciudad de México, sede subregional de la CEPAL en México.

Pérez Caldentey, E. y M. Vernengo (2008), "Back to the future: Latin America's current development strategy", The IDEA's Working Paper Series, № 07/2008.

Regolo, J. (2013), "Export diversification: how much does the choice of the trading partner?", Journal of International Economics, vol. 91, № 2, Amsterdam, Elsevier.

Requeijo, J. (1995), Economía mundial: un análisis entre dos siglos, Madrid, McGraw-Hill.

Samen, S. (2010), "A primer on export diversification: key concepts, theoretical underpinnings and empirical evidence", Documento de Trabajo, Washington, D.C., Instituto del Banco Mundial.

Sanguinetti, P., J. Pantano y J. Posadas (2004), "Regional integration and trade diversification in SouthSouth agreements: evidence from MERCOSUR", Documento de Trabajo, Buenos Aires, Universidad Torcuato Di Tella.

Schatan, C. y otros (2008), "Integración regional e integración con Estados Unidos. El rumbo de las exportaciones centroamericanas y de República Dominicana", serie Estudios y Perspectivas, № 93 (LC/L.2862-P), Ciudad de México, sede subregional de la CEPAL en México.

Schiff, M., Y. Wang y M. Olarreaga (2002), "Trade-related techonolgy diffusion and the dynamics of North-South and South-South integration", Policy Research Working Paper, № 2861, Washington, D.C., Banco Mundial.

Schweickert, R. (1994), "Regional integration: a worthwhile strategy for catching up?", Kiel Working Papers, $N^{\circ}$ 623, Kiel, Instituto para la Economía Mundial.

Ugarteche, O. (1997), El falso dilema: América Latina en la economía global, Lima, Fundación Friedrich Ebert. Vega, L., R. Morales y R. Ayala (2012), "La violencia e inseguridad económica de los veinte años de paz", Estudios Centroamericanos (ECA), vol. 67, № 728, Universidad Centroamericana José Simeón Cañas.

Vernengo, M. (2015), “Una lectura crítica al modelo de Thirlwall”, Investigación Económica, vol. 74, № 292, Ciudad de México, Universidad Nacional Autónoma de México (UNAM).

Viner, J. (1950), The Customs Union Issue, Nueva York, Carnegie Endowment for International Peace.

WITS (Solución Comercial Integrada Mundial) (2016), 9 de septiembre [en línea] https://wits.worldbank.org/ default.aspx?lang=es. 